\title{
Tecmides: um plugin para descoberta de alunos desanimados no ambiente Moodle
}

\author{
Luís Augusto W. Mercado ${ }^{1}$, Diego N. Carmona ${ }^{1}$, \\ Fabricia Damando Santos ${ }^{2}$, Leandro Krug Wives ${ }^{1}$, Magda Bercht ${ }^{1}$ \\ ${ }^{1}$ PGIE - CINTED, UFRGS \\ Porto Alegre - RS - Brazil \\ \{lawmercado, dncarmona, wives, bercht\}einf.ufrgs.br \\ ${ }^{2}$ UERGS \\ Guaíba - RS - Brazil \\ fabricia-santos@uergs.edu.br
}

\begin{abstract}
Resumo. Este artigo descreve um software desenvolvido como um plugin para a plataforma Moodle. Tal plugin foi desenvolvido dentro do âmbito do projeto Tecmides, que visa analisar dados de alunos em Ambientes Virtuais de Ensino e Aprendizagem a fim de identificar o seu estado de ânimo, em especial, alunos desanimados. O objetivo é alertar o professor sobre alunos que possam estar nessa situação de modo a possibilitar a tomada de alguma ação pedagógica ou de comunicação visando melhorar esse estado de ânimo.
\end{abstract}

\section{Cenário de Uso}

A afetividade pode influenciar na aprendizagem do aluno, principalmente com relação aos aspectos negativos, frustrações, sensações de solidão, desânimo, fazendo com que o aluno possa, inclusive, desistir de um curso, tornando-se uma problemática no ensino. Identificar esses aspectos em cursos à distância torna-se desafiador para o professor devido à distância temporal e assincronicidade desse meio. Nos cursos à distância, essa possibilidade pode ser permitida através das análises dos dados das interações do aluno no ambiente, porém, o volume de dados existentes torna-se muito grande para ser analisado pelo professor, fazendo com que seja mais difícil realizar essa identificação [Santos 2016].

O software apresentado integra o Ambiente Virtual de Ensino e Aprendizado (AVEA) Moodle [Moodle Project 2018] e a heurística de descobrimento de desânimo fundamentada em [Santos 2016], visando facilitar a análise de dados de atividade dos alunos na plataforma, provendo para o professor uma visão mais detalhada da situação do estado de ânimo dos estudantes.

Este software pode ser utilizado por alunos do ensino superior e médio, uma vez que os estudantes devem estar habituados ao uso de AVEAs. Por contar com dados de atividades dos alunos na plataforma Moodle, o software apresenta melhores resultados se aplicado a cursos com uso intenso de AVEA (normalmente cursos na modalidade de ensino a distância: cursos EAD). O software é destinado ao professor ou tutor da disciplina na forma de ferramenta de auxílio pedagógico, enquanto que possibilita ao aluno prover informações que contribuam para a efetividade desta ferramenta. 
VII Congresso Brasileiro de Informática na Educação (CBIE 2018)

Anais dos Workshops do VII Congresso Brasileiro de Informática na Educação (WCBIE 2018)

\section{Desenvolvimento}

O software possui três componentes principais: (i) um questionário inicial que procura avaliar o estado de ânimo dos alunos; (ii) o módulo de mineração dos dados; e (iii) o módulo de análise de ânimo dos alunos. Os componentes (i) e (iii) fazem parte diretamente do plugin para a plataforma Moodle, enquanto que o componente (ii), embora funcione em conjunto com a extensão, é implementado de forma independente.

O plugin, que abrange os componentes (i) e (iii), foi desenvolvido na linguagem de programação PHP [The PHP Group 2018], que também é utilizada para desenvolvimento da plataforma Moodle e outras aplicações para a web. A visualização dos resultados no plugin consiste na integração de HTML, CSS e Javascript, para, respectivamente, estruturação, estilização e dinamicidade na apresentação dos resultados da análise dos dados realizada pelo software. Para a mineração de dados, no contexto do software, a obtenção dos padrões que identificam os alunos desanimados, foi utilizado minerador Weka [Hall et al. 2009], conforme indicado em [Santos 2016], escrito na linguagem Java [Oracle Corporation 2018]. Pelo fato de o minerador escolhido ser desenvolvido na linguagem Java, o componente (ii) foi implementado na mesma linguagem. Como o plugin e o componente de mineração foram implementados em linguages de programação diferentes, foi necessário utilizar uma tecnologia para comunicação entre esses dois subsistemas. Para isso, foi utilizado a tecnologia Webservice, que possibilita uma maneira protocolada de comunicação entre sistemas diferentes. O componente de mineração, é, portanto, um servidor Webservice integrado ao Weka, acessível pelo servidor web dedicado ao projeto. Essa integração é apresentada na figura 1, que evidencia a estrutura geral do software.

Parte da verificação do software foi realizada ao comparar o processo de descobrimento de aluno desanimado implementado neste com o processo manual descrito em [Santos 2016], verificando as entradas e saídas produzidas por ambos em cada uma das etapas da heurística proposta. A verificação dos resultados de forma prática está em andamento com novas turmas de teste. As informações das turmas de teste são obtidas de ambientes Moodle em produção (ou seja, que estão em constante uso por uma instituição de ensino), com as devidas autorizações dos professores e alunos envolvidos. Em seguida, esses dados, importados da plataforma Moodle, são incorporados na instalação de teste para experimentação, avaliação e verificação do software.

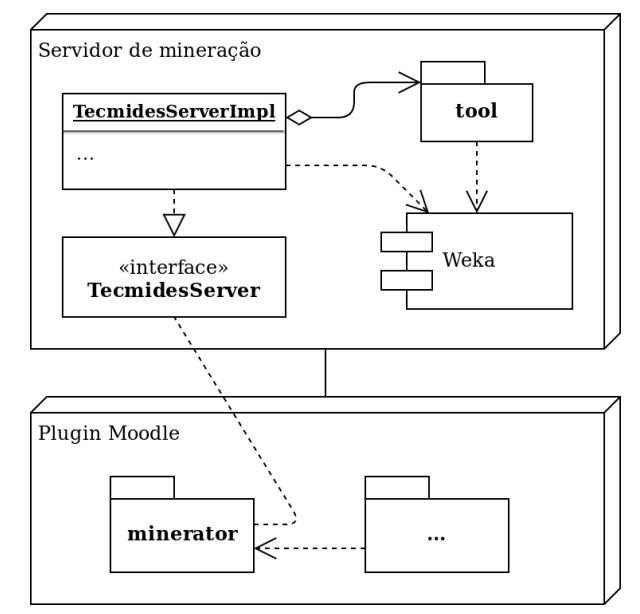

Figura 1. Diagrama representando a estrutura do software 
VII Congresso Brasileiro de Informática na Educação (CBIE 2018)

Anais dos Workshops do VII Congresso Brasileiro de Informática na Educação (WCBIE 2018)

\section{Apresentação do software}

O primeiro componente do software diz respeito ao questionário que procura avaliar o estado de ânimo do aluno. Este questionário é aplicado aos alunos para auxiliar na criação de um perfil dos participantes, que aliado aos dados de atividades dos mesmos na plataforma Moodle, contribui para a busca por padrões que sejam suficientes para segmentar os estudantes em alunos desanimados e alunos que não estão desanimados, obtendo-se assim o modelo utilizado e aperfeiçoado posteriormente pelo software. O questionário é aplicado apenas no início da disciplina, porém a análise dos dados, tanto os do perfil do aluno quanto os de atividade deste, se aplica durante todo o andamento da disciplina, pois a atividade do aluno varia durante esta, possibilitando, assim, um aperfeiçoamento do modelo.

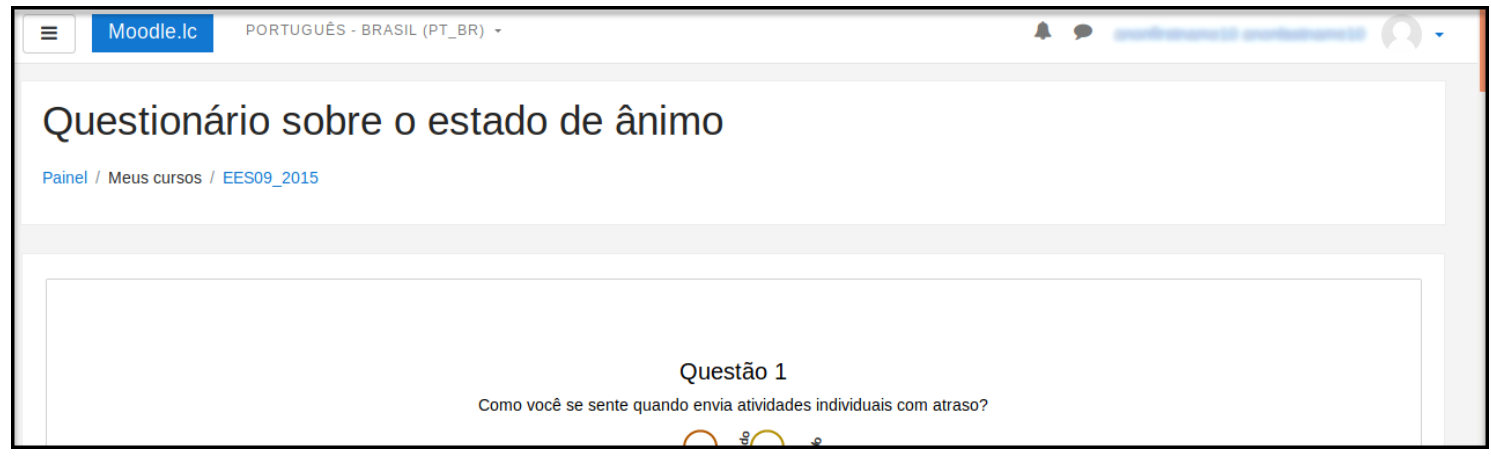

(a) Componente de questionário

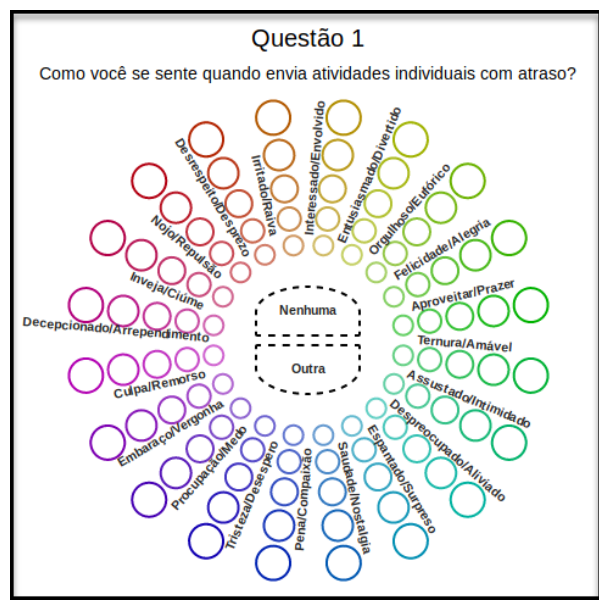

(b) Questão com roda de sentimentos

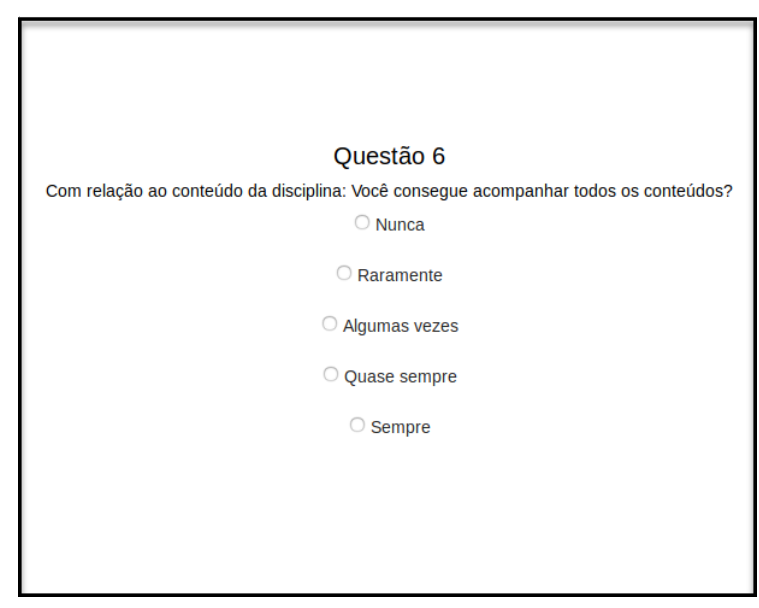

(c) Questão de Múltipla escolha

Figura 2. Componente - Questionário sobre o estado de ânimo

A figura 2 demonstra este primeiro componente, o (a) questionário sobre o estado de ânimo dos alunos. Nele, as questões propostas em [Santos 2016] que apresentam maior representatividade para a geração do modelo de predição são utilizadas para analisar o estado de ânimo dos alunos, seja através da (b) roda de estados de ânimo fundamentada em [Scherer 2005] ou de (c) questões de múltipla-escolha. As questões selecionadas estão listadas em seguida, sendo as três primeiras questões que utilizam a roda de estados de ânimo e as demais de múltipla-escolha: 
VII Congresso Brasileiro de Informática na Educação (CBIE 2018)

Anais dos Workshops do VII Congresso Brasileiro de Informática na Educação (WCBIE 2018)

1. Como você se sente quando envia atividades individuais com atraso?

2. Como você se sente quando envia atividades em grupo com atraso?

3. Como você se sente quando tem dificuldade em algum conteúdo?

4. Com relação às atividades INDIVIDUAIS propostas pelo Moodle: Você as envia com atraso?

5. Com relação às atividades EM GRUPO propostas pelo Moodle: Você as envia com atraso?

6. Com relação ao conteúdo da disciplina: Você consegue acompanhar todos os conteúdos?

7. Com relação ao conteúdo da disciplina: Já teve alguma dificuldade em algum conteúdo?

Os dados obtidos por meio do questionário do primeiro componente, assim como os dados das atividades dos alunos na plataforma Moodle, são enviados como entrada para o segundo componente: o de mineração de dados. Utilizando o minerador Weka, este componente gera um conjunto de regras (potenciais padrões) que são filtradas e avaliadas, para que em seguida sejam utilizadas para classificar a propensão de desânimo dos alunos, conforme descrito em [Santos 2016].

Para a aplicação das regras geradas pelo segundo componente, usa-se o terceiro componente, o qual foi implementado em formato de relatório, este que provê uma apresentação em formato gráfico dos dados (figura 3), propiciando uma visão mais intuitiva do estado de ânimo da turma, o que facilita a identificação dos alunos propensos ao desânimo. Este relatório pode ser acessado pelo professor via Moodle, na seção Relatório, nas opções da disciplina, com o nome de 'Previsão de aluno desanimado' (figura 4). Essa opção é acessível apenas para o professor da disciplina.

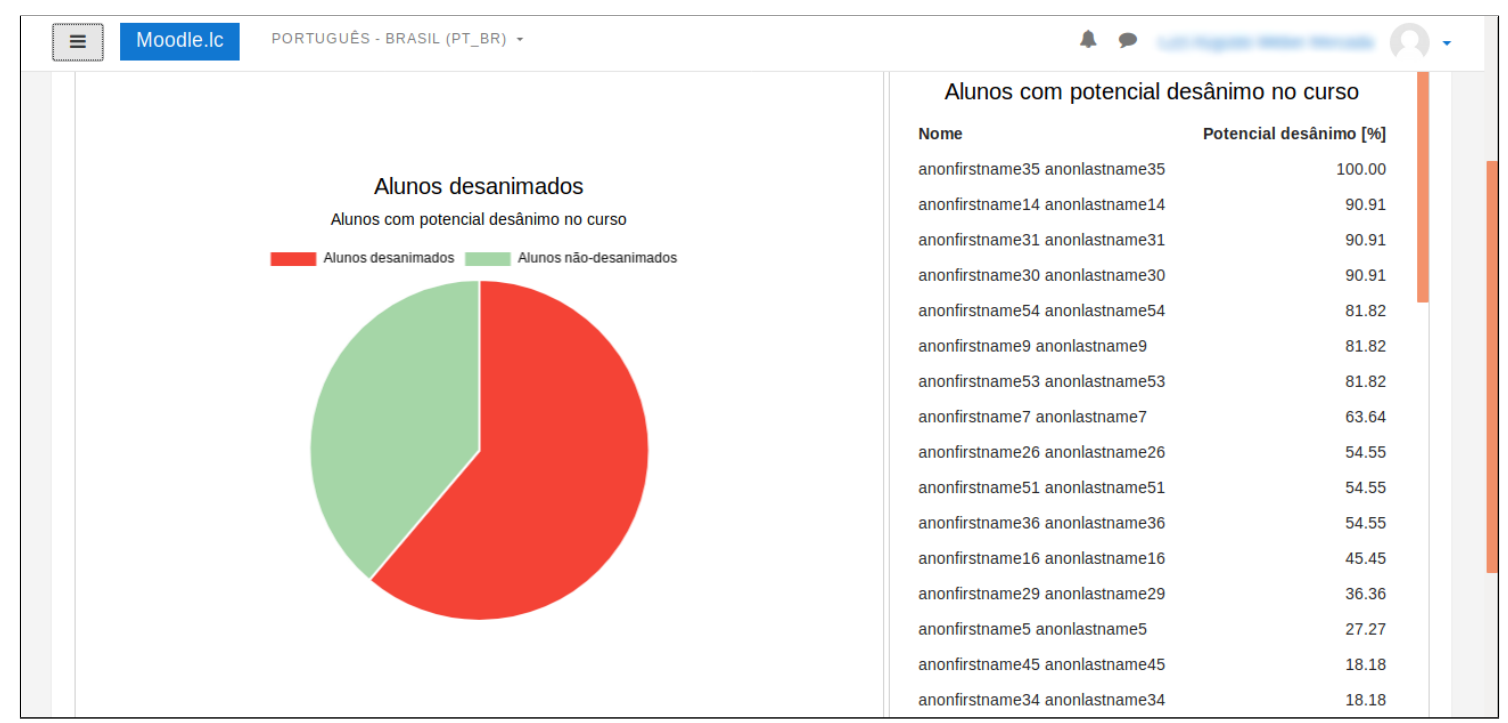

Figura 3. Relatório do estado de ânimo 
VII Congresso Brasileiro de Informática na Educação (CBIE 2018)

Anais dos Workshops do VII Congresso Brasileiro de Informática na Educação (WCBIE 2018)

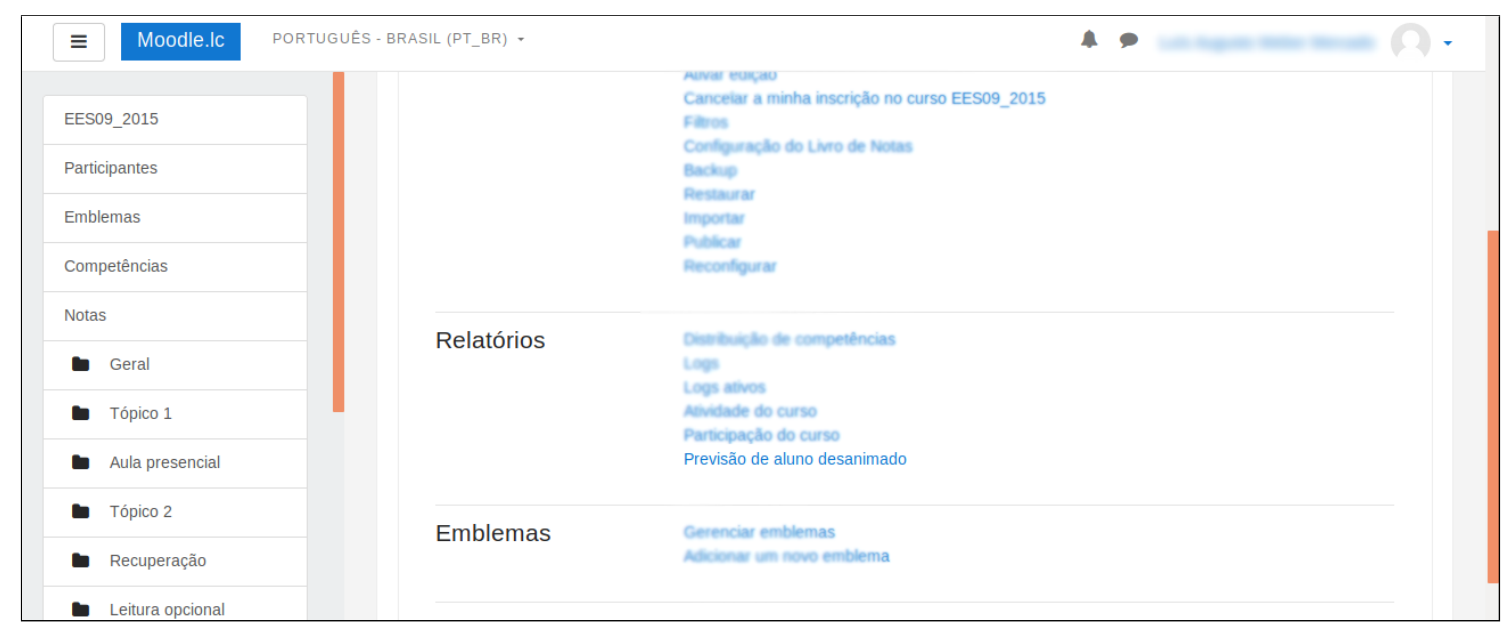

Figura 4. Relatório do estado de ânimo

O plugin desenvolvido está instalado em um servidor de testes do Moodle, disponível no servidor web do projeto Tecmides, com acesso limitado por login. Além disso, por se tratar de um plugin para um Software Livre como o Moodle, ele utiliza a mesma licença, a GNU GPLv3. O código fonte, tanto do plugin vinculado diretamente ao Moodle, como o do servidor de mineração de dados está disponível no repositório Github do projeto Tecmides. Além disso, o vídeo demonstrativo do software está disponível no YouTube.

\section{Considerações finais}

A partir do software apresentado neste artigo, o professor pode identificar alunos com potencial estado de ânimo desanimado no AVEA Moodle sem ter conhecimento técnico prévio nos conceitos que estão envolvidos na obtenção dessa informação, além de visualizar uma análise complexa de maneira simples, conforme evidenciado nas figuras 3 e 4 . A partir desse resultado obtido sobre o estado de ânimo desanimado do aluno, é possível que o professor tome iniciativas que busquem melhorar a experiência do estudante em sua disciplina.

Embora o software se encontre na fase de verificação, o mesmo é um protótipo, pois não está incorporado em nenhuma instalação da plataforma Moodle em produção. Após a fase de verificação, que opera conforme descrito na seção 2 deste artigo, dá-se a fase de validação do software, etapa esta em que serão realizados testes com os usuários finais (professores e alunos), visando validar a intuitividade da visualização dos resultados da análise realizada assim como a do questionário propostos neste protótipo.

Após as etapas de verificação e validação, o plugin estará pronto para ser incorporado no repositório oficial de extensões para a plataforma Moodle, possibilitando que o mesmo seja amplamente utilizado em qualquer instalação do AVEA Moodle que tenha suporte aos recursos utilizados. O software possibilita, também, que possam ser avaliadas diferentes metodologias de obtenção do estado de ânimo os alunos, além da proposta em [Santos 2016], devido a modularidade que este apresenta, promovendo, assim, potenciais contribuições para a área da informática e da educação. 
VII Congresso Brasileiro de Informática na Educação (CBIE 2018)

Anais dos Workshops do VII Congresso Brasileiro de Informática na Educação (WCBIE 2018)

O presente trabalho foi realizado com apoio da Coordenação de Aperfeiçoamento de Pessoal de Nível Superior - Brasil (CAPES) - Edital 03/2015 - Processo 23038.021865/2016-53 - Projeto "Descoberta do desânimo de alunos em ambientes virtuais de ensino e aprendizagem ulizando mineração de dados educacionais - TECMIDES".

\section{Referências}

[Hall et al. 2009] Hall, M., Frank, E., Holmes, G., Pfahringer, B., Reutemann, P., and Witten, I. H. (2009). The weka data mining software: an update. ACM SIGKDD explorations newsletter, 11(1):10-18.

[Moodle Project 2018] Moodle Project (2018). Moodle - open-source learning plataform.

[Oracle Corporation 2018] Oracle Corporation (2018). Java.

[Santos 2016] Santos, F. D. (2016). Descoberta do desânimo de alunos em ambientes virtuais de ensino e aprendizagem: um modelo a partir da mineração de dados educacionais.

[Scherer 2005] Scherer, K. R. (2005). What are emotions? and how can they be measured? Social science information, 44(4):695-729.

[The PHP Group 2018] The PHP Group (2018). Php: Hypertext preprocessor. 